\title{
Body Height and its Estimation Utilizing Arm Span Measurements in Male and Female Adolescents from Danilovgrad and Cetinje
}

\author{
Marina Vukotic ${ }^{1}$ \\ 'University of Montenegro, Faculty for Sport and Physical Education, Niksic, Montenegro
}

\begin{abstract}
The goal of this study was to examine the bodi height of male and female from the Danilovgrad and Cetinje, as well as the ratio of body height and arm span as an alternative assessment of body height. A total of 244 individuals ( 125 male and 119 female) participated in this research. Anthropometric measurements were taken on the basis of the International Community for the Advancement of Kinantropometry (ISAK). Methods and standard deviations in anthropometric measurements were used. The T-test has verified the differences in the arithmetic mean of anthropometric variables in relation to half of the subjects. The correlation between the body height and the arm's length was analyzed with a confidence of $95 \%$. By linear regression analysis, the prediction of the arm's range on the criterion variable is the body height at the new value of $p<0.05$. These relationships are shown as a scatter diagram. The results showed that male are $182.49 \pm 6.81 \mathrm{~cm}$ high and have a range of arms of $183.60 \pm 8.27$ $\mathrm{cm}$, female are $168.14 \pm 6.30$ in height and have a arm span of $167.07 \pm 7.36 \mathrm{~cm}$. Compared with other studies, the results of this study have shown that men and women from the Danilovgrad and Cetinje belong to a high population, higher than most of the nations in Europe. On the other hand, as expected, it has been shown that in this male and female it is possible to predict reliably the body height using a arm span However, the estimation equations obtained for men and women from the Danilovgrad and Cetinje differ from the general population, since the arm span was closer to the height of the body $(1.11 \pm 1.46 \mathrm{~cm})$ and $(1.07 \pm 1.06 \mathrm{~cm})$ than in the general population. That confirmans the need of development of special height models of montenegrin population, for everu region in Montenegro.
\end{abstract}

Key words: Stature, Arm Span, Danilovgrad, Cetinje

\section{Uvod}

Postoji veliki broj studija koji potvrđuje da je procjena tjelesne visine značajan faktor koji može uticati na procjenu statusa uhranjenosti kod odraslih ljudi (Popović, \& Bjelica, 2016, Popović \& Bjelica 2017), ali i na procjenu razvoja djece. Zatim na ocjenu osnovnih energetskih poterba, prilagođavanja mjera fizičkog kapaciteta, kao i na procjenu količine uzimanja određenih ljekova i niza drugih stvari, kao što je procjena mišićne snage, mataboličkih procesa, kapaciteta pluća i sl (Mohanty, Babu, \& Nair, 2001; Golshan, Amra, \& Hoghogi, 2003; M. Gol- shan, Crapo, Amra, Jensen, \& R. Golshan, 2007; Ter Goon, Toriola, Musa, \& Akusu, 2011). Međutim, tjelesna visina se ne može uvijek precizno utvrditi, prije svega kod slučajeva kao što su npr. paraliza, fraktura, amputacija, i razni deformiteti kao što su npr. skolioza i kifoza (Mašanović, 2017). Iz tog razloga, neophodno je procijeniti relativnu tjelesnu visinu iz drugih pouzdanih antropometrijskih indikatora kao što su dužina ruke i stopala, visina koljena, dužina podlaktice, dužina grudne kosti, sjedeća visina, dužine lopatice, dužina ruke, kao i niza drugih manje pouzdanih indikatora (Bjelica, Popović \& Akpi-

Correspondence:

Montenegro M.Vukotić

Gport University of Montenegro, Faculty for Sport and Physical Education, Narodne omladine bb, 81400 Niksic, Montenegro E-mail: marinavuk@ac.me 
nar, 2014; Bjelica, Popović \& Akpinar, 2015; Bjelica, Popović, \& Akpinar, 2016; Gardašević, Rasidagić, Krivokapić, Ćorluka, \& Bjelica, 2017; Bjelica, Popović \& Akpinar, 2017 \& Popović, 2017). Svi navedeni antropometrijski indikatori, koji se koriste kao alternativa za procjenu relativne tjelesne visine, veoma su važni u svim slučajevima gore pobrojanim, a u kojima je tjelesna visina značajna te se ne može izmjeriti standardnom metodom (Popović, 2017).

Značajan broj istraživanja upućuje na korisnost primjenjivanja različitih tjelesnih parametara u procjenjivanju relativne tjelesne visine (Popović, Bjelica, Petković, Muratović, \& Georgiev, 2014; Popović, Milašinović, Matić, Gardašević, \& Bjelica, 2016; Popović, Milašinović, Jakšić, Vasiljević, \& Bjelica, 2016; Popović, Bjelica, Milašinović, \& Gardašević, 2016; Milašinović, Popović, Bjelica, \& Vasiljević, 2016; Popović, Bjelica, Milašinović, Gardašević, \& Rašidagić, 2016; Popović, \& Bjelica, 2016, Popović, Arifi, \& Bjelica, 2017a; Popović, \& Bjelica, 2017; Popović, Gardašević, Mašanović, Arifi, \& Bjelica, 2017b) a ispostavilo se da je raspon ruku, upravo najpouzdaniji od svih ostalih (Mohanty et al., 2001; Ter Goon et al., 2011). Sa druge strane, široko je poznato da su tjelesna visina i tjelesne proporcije specifične kada se govori o populacijama koje žive na Dinaridima. Crnogorci danas djelimično pripadaju dinarskoj rasnoj klasifikaciji (Bjelica i sar., 2012), a autori vjeruju da su razlog većoj visini muške i ženske populacije u odnosu na prosječnog ispitanika sa Dinarskih planina, uglavnom mnogo bolji uslovi za život. Dakle, svrha ove studije je dvostruka. Prvi cilj je bio ispitati tjelesnu visinu kod adolescenata muškog i ženskog pola sa područja Danilovgrada i Cetinja kako bi se utvrdilo da li su to mjesta gdje stanovništvo Dinarida, kao što su autori vjerovali, može doseći puni potencijal, dok je drugi cilj bio ispitvanje odnosa tjelesne visine i raspona ruku kao alternativne mjere procjene tjelesne visine.

\section{Metod}

U ovoj studiji uzorak ispitanika obuhvata 244 adolescenata (125 isptanika muškog pola i 119 ispitanika ženskog pola) iz Danilovgrada i Cetinja. Prosječna starost ispitanika muškog pola bila je $18.28 \pm 0.73$ godina i ispitanika ženskog pola
$18.17 \pm 0.68$ godina. Takođe je važno naglasiti da su autori isključili iz studije adolescente s tjelesnim deformacijama (skolioza, kifoza i lordoza) koje bi mogle uticati na visinu tijela ili raspon ruku, i bez informisanja o tome. Ispitanici koji nijesu sa područja Danilovgrada i Cetinja takođe su bili isključeni iz ovog istraživanja. Antropometrijska mjerenja, uključujući tjelesnu visinu tijela i raspon ruku, uzeta su prema protokolima Međunarodne zajednice za unapređenje kinantropometrije (ISAK). Starost ispitanika utvrđivana je njihovim saopštavanjem datuma rođenja.

Statistička obrada podataka je urađena pomoću statističkog programa SPSS 20.0. Za obije antropometrijske varijable obrađeni u centralni i disperzivni parametri u okviru osnovne statistike i to: raspon (minimalna i maksimalna vrijednost), aritmetička sredina i standardna devijacija. T-testom su provjerene razlike aritmetičkih sredina antropometrijskih varijabli u odnosu na pol ispitanika. Veza između tjelesne visine i raspona ruku je obrađena korelacionom analizom s pouzdanošću od 95\%. Linearnom regresionom analizom je utvrđena predikcija raspona ruku na kriterijsku varijablu tjelesna visina na novou značajnosti $\mathrm{p}<0.05$., ovi odnosi prikazani su u vidu dijagrama raspršenja

\section{Rezultati}

Rezultati centralnih i disperzionih parametara za ispitanike oba pola nalaze se u tabeli 1 . Aritmetička sredina $\mathrm{u}$ varijabli tjelesna visina kod ispitanika muškog pola iznosi $182.49 \pm 6.81 \mathrm{~cm}$, a u varijabli raspon ruku $183.60 \pm 8.27 \mathrm{~cm}$, što je za $1.11 \pm 1.46 \mathrm{~cm}$ manje, a to potvrđuje da je prosječna tjelesna visina kod ispitanika muškog pola manja u odnosu na raspon ruku. Kod ispitanika ženskog pola aritmetička sredina $\mathrm{u}$ varijabli tjelesna visina iznosi $168.14 \pm 6.30 \mathrm{~cm}$, a u varijabli raspon ruku $167.07 \pm 7.36 \mathrm{~cm}$, što je za $1.07 \pm 1.06 \mathrm{~cm}$ više, a to potvrđuje da je prosječna tjelesna visina kod ispitanika ženskog pola veća u odnosu na raspon ruku.

Razlike aritmetičkih sredina antropometrijskih varijabli u odnosu na pol ispitanika su statistički značajne s koeficijentima (tjelesna visina $\mathrm{t}=17.060 ; \mathrm{p}<0.000$ a raspon ruku $\mathrm{t}=16.452 ; \mathrm{p}<0.000)$.

Tabela 1. Centralni i disperzivni parametri antropometrijskih karakteristika

\begin{tabular}{ccc}
\hline \multirow{2}{*}{ Ispitanici } & $\begin{array}{c}\text { Tjelesna visina } \\
\text { (Aritm.sredina } \pm \text { SD) }\end{array}$ & $\begin{array}{c}\text { Raspon ruku } \\
\text { (Aritm.sredina } \pm \text { SD) }\end{array}$ \\
\hline \multirow{2}{*}{ Muški } & $165.1-203.30$ & $152.1-208.3$ \\
& $(182.49 \pm 6.81)$ & $(183.60 \pm 8.27)$ \\
\multirow{2}{*}{ Ženski } & $151.5-184.0$ & $147.2-182.1$ \\
& $(168.14 \pm 6.30)$ & $(167.07 \pm 7.36)$ \\
\hline
\end{tabular}

U tabeli 2 prikazani su rezultati korelacione analize između tjelesne visine i raspona ruku s pouzdanošću od 95\% za ispitanike oba pola. Povezanost, odnosno korelacija između tjelesne visine i raspona ruku je statistički značajna na nivou $\mathrm{p}<0.000$, kod ispitanika muškog i kod ispitanika ženskog pola. Koeficijenti korelacije su veoma visoki i kod ispitanika muškog pola taj koeficijent iznosi 0.749 , a kod ispitanika ženskog pola 0.845 .

Tabela 2. Korelaciona analiza između tjelesne visine i raspona ruku

\begin{tabular}{cccc}
\hline Ispitanici & Koeficijent korelacije & $\begin{array}{c}\text { Interval pouzdanosti } \\
\text { od 95\% }\end{array}$ & $\begin{array}{c}\text { Nivo } \\
\text { značajnosti }\end{array}$ \\
\hline Muški & 0.749 & $0.573-0.863$ & 0.000 \\
Ženski & 0.845 & $0.795-0.885$ & 0.000 \\
\hline
\end{tabular}

Rezultati linearne regresione analize su prikazani u tabeli 3. Koeficijenti regresije kod ispitanika oba pola su istovjetni s koeficijentima korelacije iz prethodne analize i veoma viso- ki. Visoke vrijednosti koeficijenta regresije (muškarci: 0.749; žene: 0.845$)$ znače da je predikcija raspona ruku na tjelesnu visinu statistički značajna, tj. raspon ruku može da predvidi 
tjelesnu visinu kod ispitanika oba pola sa područja Danilovgrada i Cetinja (muškarci $\mathrm{t}=12.480 ; \mathrm{p}<0.000$, žene $\mathrm{t}=16.957$; $\mathrm{p}<0.000$ ). To potvrđuju i koeficijenti determinacije, gdje za muškarce taj koeficijent objašnjava $61.6 \%$ varijabiliteta, a kod žena $72.1 \%$ varijabiliteta, pa samo mali procenat ostaje neobjašnjen, odnosno pod uticajem drugih faktora koji nijesu bili obuhvaćeni ovim istraživanjem.

Tabela 3. Rezultati linearne regresione analize (predikcija raspona ruku na tjelesnu visinu)

\begin{tabular}{cccccc}
\hline Ispitanici & $\begin{array}{c}\text { Koeficijent } \\
\text { regresije }\end{array}$ & $\begin{array}{c}\text { Standardna } \\
\text { greška }\end{array}$ & $\begin{array}{c}\text { Koeficijent } \\
\text { determinacije (\%) }\end{array}$ & t vrijednost & $\begin{array}{c}\text { Nivo } \\
\text { značajnosti }\end{array}$ \\
\hline Muški & 0.749 & 4.545 & 61.6 & 12.480 & 0.000 \\
Ženski & 0.845 & 3.403 & 72.1 & 16.957 & 0.000 \\
\hline
\end{tabular}

Mjerenja tjelesne visine i raspona ruku, kao i njihova veza prikazani su udruženo za ispitanike oba pola pomoću skater

dijagrama (dijagram 1).

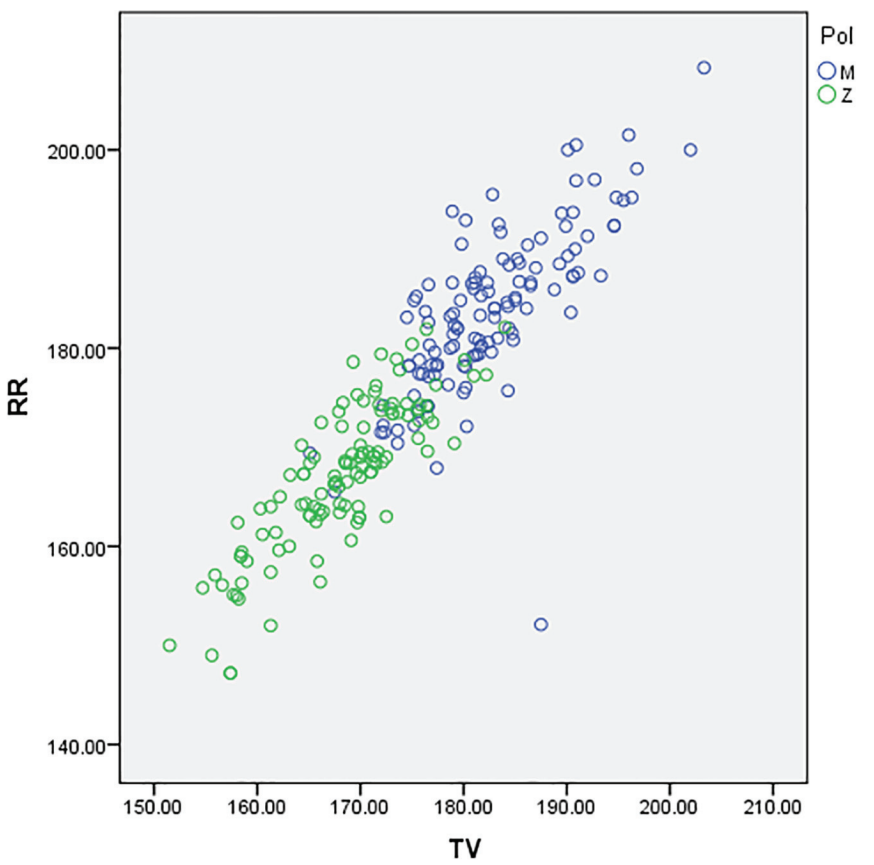

Dijagram 1. Skater dijagram i veza između raspona ruku i tjelesne visine među oba pola

\section{Diskusija}

Prvi cilj ove studije je bio ispitati tjelesnu visinu kod adolescenata muškog i ženskog pola sa područja Danilovgrada i Cetinja da bi se utvrdilo da li je to mjesto gdje stanovništvo Dinarida, kao što su autori vjerovali, može doseći puni potencijal, dok je drugi cilj bio ispitivanje odnosa tjelesne visine i raspona ruku kao alternativne procjene tjelesne visine. $\mathrm{Na}$ osnovu dobijenih rezultata, konstatujemo da je prosječna tjelesna visina ispitanika muškog i ženskog pola slična visini najviših ljudi u Evropi. Takođe, ovo istraživanje je pokazalo, da je prosječna tjelesna visina adolescenta iz Danilovgrada i Cetinja, skoro ista kao prosječna tjelesna visina u centralnoj regiji Crne Gore (Vujović, Bubanja, Tanase, \& Milašinović, 2015) i južnoj regiji Crne Gore (Milašinović, i sar.,2016). Može se vidjeti da u Crnoj Gori postoje varijacije kada su regioni u pitanju: sjeverna, centralana i južna regija (Popović, 2016). Interesantno je pomenuti Kosovo, jer specifičnosti postoje u odnosu na druge populacije kada je odnos tjelesne visine i raspona ruku u pitanju, i takođe se javljaju regionalne razlike (Arifi, Bjelica, Sermaxhaj, Gardašević, Kezunović, \& Popović, 2017a; Arifi, Sermaxhaj, Zejnullahu-Raçi, Alaj, \& Metaj, 2017b; Gardašević, Mašanović, \& Arifi, 2018a, Gardašević, Mašanović,\& Arifi, 2018b; Gardašević, Mašanović, \& Arifi, 2018c; Gardašević, 2018; Mašanović, Gardašević, \& Arifi, 2018a; Mašanović,
Gardašević, \& Arifi, 2018b; Mašanović, Gardašević, \& Arifi, 2018c; Mašanović, Gardašević, \& Arifi, 2018d; Mašanović, Gardašević, \& Arifi, 2018e; Mašanović, Gardašević, \& Arifi, 2018f; Mašanović, Gardašević, \& Arifi, 2018g; Mašanović, 2018; Mašanović, 2018a; \& Mašanović, 2018b). Prosječna visina Crnogoraca i Crnogorki iz Danilovgrada i Cetinja viša je od prosječne visine Litvanaca (Popović, Bjelica, \& Hadžić, 2014), prosječne visine Srba (Popović, Bjelica, Molnar, Jakšić, \& Akpinar, 2013), prosječne visine Islanđana (Bjelica i sar., 2012) i mnogih drugih naroda. Međutim, postoji hipoteza da Crnogorci još uvijek nijesu dostigli svoj puni genetski potencijal, budući da su bili izloženi djelovanju spoljašnjih uticaja (ratovi, slaba ekonomska situacija, itd.) u posljednjih nekoliko decenija (Popović i sar., 2013), iako je taj uticaj bio manji u centralnom području Crne Gore. Stoga, autori vjeruju da su ove okolnosti negativno uticale na sekularni trend $\mathrm{u}$ Crnoj Gori, dok se očekuje da će se sekularne promjene koje utiču na visinu povećati u narednih 20 godina.

S druge strane, kao što je i očekivano, raspon ruku pouzdano predviđa tjelesnu visinu kod adolcenata. Međutim, jednačine procjene koje su dobijene kod adolescenata iz Danilovgrada i Cetinja, su različite u odnosu na opštu populaciju, budući da je raspon ruku kod muškaraca približniji tjelesnoj visini $(1.11 \pm 1.46 \mathrm{~cm})$ više nego kod opšte populacije, i kod 
žena $(1.07 \pm 1.06)$ više nego kod opšte populacije (Bjelica i sar., 2012). To potvrđuje nužnost razvijanja posebnih modela visine kod crnogorske populacije odnosno za svaku regiju u Crnoj Gori.

\section{Acknowledgements}

There are no acknowledgements.

\section{Conflict of Interest}

The authors declare that there are no conflict of interest.

Received: 19 May 2018| Accepted: 23 June 2018 | Published: 13 July 2018

\section{References}

Arifi, F., Bjelica, D., Sermaxhaj, S., Gardašević, J., Kezunović, M., \& Popović, S. (2017a). Stature and its Estimation Utilizing Arm Span Measurements in Kosovan Adults: National Survey. International Journal of Morphology, 35(4), 1161-7

Arifi, F., Sermaxhaj, S., Zejnullahu-Raçi, P., Alaj, I., \& Metaj, Z. (2017b). Stature and its estimation utilizing arm span measurements of both gender adolescents from northern region in Kosovo. Acta Kinesiologica, 11(1), 49-52.

Bjelica, D., Popović, S., \& Akpinar, S. (2014). Book of Abstracts of the 11th International Scientific Conference on Transformation Process in Sport "Sport Performance". Podgorica: Montenegrin Sports Academy.

Bjelica, D., Popović, S., \& Akpinar, S. (2015). Book of Abstracts of the 12th International Scientific Conference on Transformation Process in Sport "Sport Performance". Podgorica: Montenegrin Sports Academy.

Bjelica, D., Popović, S., \& Akpinar, S. (2016). Book of Abstracts of the 13th International Scientific Conference on Transformation Process in Sport "Sport Performance". Podgorica: Montenegrin Sports Academy.

Bjelica, D., Popović, S., \& Akpinar, S. (2017). Book of Abstracts of the 14th International Scientific Conference on Transformation Process in Sport "Sport Performance". Podgorica: Montenegrin Sports Academy.

Bjelica, D., Popović, S., Kezunović, M., Petković, J., Jurak, G. \& Grasgruber, P. (2012). Body Height and Its Estimation Utilizing Arm Span Measurements in Montenegrin Adults. Anthropological Notebooks, 18(2), 69-83.

Gardašević, J. (2018). Standing Height/Sitting Height Ration in Eastern-Kosovan Adolescents. Retrieved from SSRN's eLibrary: https://ssrn.com/ abstract $=3141566$

Gardašević, J. (2018). Standing Height/Tibia Length Ration in Western-Kosovan Adolescents. Retrieved from SSRN's eLibrary: https://ssrn.com/ abstract $=3138101$

Gardašević, J., Mašanović, B., Arifi, F. (2018a). Relationship Tibia Length/Standing Height in Central-Kosovan Adolescents. Retrieved from SSRN's eLibrary: https://ssrn.com/abstract=3138122

Gardašević, J., Mašanović, B., Arifi, F. (2018b). Relationship Tibia Length/Standing Height in Northern-Kosovan Adolescents. Retrieved from SSRN's eLibrary: https://ssrn.com/abstract=3138112

Gardašević, J., Mašanović, B., Arifi, F. (2018c). Relationship Tibia Length/Standing Height in Southern-Kosovan Adolescents. Retrieved from SSRN's eLibrary: https://ssrn.com/abstract=3138105ž

Gardašević, J., Rasidagić, F., Krivokapić, D., Čorluka, M., \& Bjelica, D. (2017) Stature and Its Estimation Utilizing Arm Span Measurements in Male Adolescents from Herzeg Bosnia Entity in Bosnia and Herzegovina. Montenegrin Journal of Sports Science and Medicine, 6(1), 37-44.

Golshan, M., Amra, B., \& Hoghogi, M.A. (2003). Is arm span an accurate measure of height to predict pulmonary function parameters? Monaldi Archives for Chest Disease, 59(3), 189-92.

Golshan, M., Crapo, R.O., Amra, B., Jensen, R.I., \& Golshan, R. (2007). Arm span as an independent predictor of pulmonary function parameters: validation and reference values. Respirology, 12(3), 361-6.

Marfell-Jones, M., Olds, T., Stewart, A., \& Carter, L. (2006). International standards for anthropometric assessment. Potchesfstroom: International Society for the Advancement of Kinanthropometry.

Mašanović, B. (2017). Relationship between arm span measurements and body height in Dinaric Alpes population: A systematic review. Journal of Anthropology of Sport and Physical Education, 1(1), 33-7.

Mašanović, B. (2018). Standing Height and its Estimation Utilizing Arm Spam and Foot Length Measurements in Dinaric Alps Population: A Systematic Review. Sport Mont, 16(2), 1-6.

Mašanović, B. (2018a). Standing Height/Sitting Height Relationhip in Western Region in Kosovo. Retrieved from SSRN's eLibrary: https://ssrn. com/abstract $=3138518$

Masanovic, B. (2018b). Tibia Length and Standing Heigh Relationshipt in Eastern Region of Kosovo. Retrieved from SSRN's eLibrary: https://ssrn. com/abstract $=3143118$
Mašanović, B., Gardašević, J., \& Arifi, F. (2018a). Sitting Height/Standing Height Relationship in Southern Region of Kosovo. Retrieved from SSRN's eLibrary: https://ssrn.com/abstract=3138523

Mašanović, B., Gardašević, J., \& Arifi, F. (2018b). Sitting Height/Standing Height Relations in Central Region of Kosovo. Retrieved from SSRN's eLibrary: https://ssrn.com/abstract=3138525

Mašanović, B., Gardašević, J., \& Arifi, F. (2018c). Sitting Height/Standing Height Relationship Measurements in Northern Region of Kosovo. Retrieved from SSRN's eLibrary: https://ssrn.com/abstract=3138526

Mašanović, B., Gardašević, J., \& Arifi, F. (2018d). Relationship between foot length measurements and body height: A prospective regional study among adolescents in eastern region of Kosovo. Sport Mont, 16(1), 9-13. doi: 10.26773/smj.180202

Mašanović, B., Gardašević, J., \& Arifi, F. (2018e). Relationship between Foot Length Measurements and Body Height: A Prospective Regional Study among Adolescents in Northern Region of Kosovo. Anthropologie-International Journal of Human Diversity and Evolution, in pres, https://doi. org/10.26720/anthro.18.01.23.1

Mašanović, B., Gardaševic, J., \& Arifi, F. (2018f). Relationship between Foot Length Measurements and Body Height: A Prospective Regional Study among Adolescents in Central Region of Kosovo. Journal of Contemporary Medical Sciences, in press

Mašanović, B., Gardašević, J., \& Arifi, F. (2018g). Standing Height and its Estimation Utilizing Foot Length Measurements in Adolescents from Southern Region in Kosovo. Sport Mont, 16(2), 27-31.

Milašinović, R., Popović, S., Bjelica, D., \& Vasiljević, I. (2016). Body height and its estimation utilizing arm span measurements in female adolescents from northern region in Montenegro. In Book of Abstracts of 4th International Scientific Conference "Exercise and Quality of Life" (39), Novi Sad: Faculty of Sport and Physical Education.

Milašinović, R., Popović, S., Jakšić, D., Vasilejvić, I. \& Bjelica, D. (2016b). Stature and its Estimation Utilizing Arm Span Measurements in Feale Adolescents from Southern Region in Montenegro. Sport Mont, 14(3), 15-8.

Milašinović, R., Popović, S., Matić, R., Gardašević, J. \& Bjelica, D. (2016). Body Height and its Estimation Utili Span Measurements in Male Adolescents from Southern Region in Montenegro. Sport Mont, 14(2), 21-3.

Mohanty, S.P., Babu, S.S., \& Nair, N.S. (2001). The use of arm span as a predictor of height. A study of South Indian women. Journal of Orthopedics Surgery, 9(1), 19-23.

Popović, S. \& Bjelica, D. (2016). Body Height and its Estimation Utilizing Arm Span Measurements in Kosovan Adolescence: National Survey. In Abstract Book of International Eurasian Conference on Sport, Education, and Society (9), Antalya: International Science Culture and Sport Association.

Popović, S. (2017). Local Geographical Differences in Adult Body Height in Montenegro. Montenegrin Journal of Sports Science and Medicine, 6(1), 81-7.

Popović, S. Gardašević, J., Mašanović, B., Arifi, F., \& Bjelica, D. (2017b). Standing Height and its Estimation Utilizing Foot Length Measurements in Adolescents from Western Region in Kosovo. Sport Mont, 15(3), 3-7.

Popović, S., \& Bjelica, D. (2016). Body Height and its Estimation Utilizing Arm Span Measurements in Kosovan Adolescence: National Survey. In Abstract Book of International Eurasian Conference on Sport, Education, and Society (9), Antalya: International Science Culture and Sport Association.

Popović, S., \& Bjelica, D. (2017). Body Height and its Estimation Utilizing Foot Length Measurements in Kosovan Adults: National Survey. In Abstract Book of the Sport Science Conference AESA 2017 (2), Amol: Faculty of Sport Sciences, Shomal University; Asian Exercise and Sport Science Association.

Popović, S., Arifi, F., \& Bjelica, D. (2017a). Standing Height and its Estimation Utilizing Foot Length Measurements in Kosovan Adults: National Survey. International Journal of Applied Exercise Physiology, 6(2), 1-7.

Popović, S., Bjelica, D., \& Hadžić, R. (2014). Average body height of adolescents in Montenegro. In Proceedings book of the 13th International Sport Sciences Congress (462-463). Konya: Selcuk University

Popović, S., Bjelica, D., Milašinović, R., \& Gardašević, J. (2016). Body height and its estimation utilizing arm span measurements in male adolescents from northern region in Montenegro. In Book of Abstracts of 4th International Scientific Conference "Exercise and Quality of Life" (38), Novi Sad: Faculty of Sport and Physical Education.

Popović, S., Bjelica, D., Milašinović, R., Gardašević, J., \& Rašidagić, F. (2016). Body height and its estimation utilizing arm span measurements in male adolescents from Herzeg-Bosnia entity in Bosnia and Herzegovina. In Book of Abstracts of IUAES Inter Congress "World anthropologies and privatization of knowledge: engaging anthropology in public" (148), Dubrovnik: International Union of Anthropological and Ethnological Sciences. 
Popović, S., Bjelica, D., Molnar, S., Jaksic, D., \& Akpinar, S. (2013). Body Height and Its Estimation Utilizing Arm Span Measurements in Serbian Adults. International Journal of Morphology, 31(1), 271-9.

Popović, S., Bjelica, D., Petković, J., Muratović, A. \& Georgiev, G. (2014). Body Height and Its Estimation Utilizing Arm Span Measurements in Macedonian Adolescents. In Abstract Book of the 7th Conference for Youth Sport (40), Ljubljana: Faculty of Sport, University of Ljubljana.

Popović, S., Milašinović, R., Matić, R., Gardašević, J., Bjelica, D. (2016). Body height and its estimation utilizing arm span measurements in male adolescents from southern region in Montenegro. In Book of Abstracts of the 13th International Scientific Conference on Transformation Process in Sport "Sport Performance" (29-30), Podgorica: Montenegrin Sports Academy. Scientific Conference on Transformation Process in Sport "Sport Performance" (30), Podgorica: Montenegrin Sports Academy.

Ter Goon, D., Toriola, A.T., Musa, D.I., \& Akusu, S. (2011). The relationship between arm span and stature in Nigerian adults. Kinesiology, 43(1), 38-43. Vujović, D., Bubanja, M., Tanase, G. D., \& Milašinović, R. (2015). Body Height and Its Estimation Utilizing Arm Span Measurements in Male Adolescents from Central Region in Montenegro. Sport Mont, 12(43-45), 283-8. 